\title{
Relevance of Blockchain in the Global World
}

\author{
Chandan Thakur ${ }^{1 *}$, Vipul Kumar Katiyar², Sonu Kumar ${ }^{3}$ \\ ${ }^{1}$ Associate Professor, Department of Marketing, Universal Business School, Karjat, India \\ ${ }^{2,3}$ Student, Department of Marketing, Universal Business School, Karjat, India \\ *Corresponding author: chandan_t@yahoo.com
}

\begin{abstract}
The academic and business community discusses the research avenues and practical implementations of blockchains continuously with the ongoing growth and implementation of blockchain technologies. The blockchain also has its advantages in the economy, manufacturing, medical and other industries. Most view Blockchain as a perturbing key technology. Although several academics have recognized the importance of blockchain, blockchain technology is still in its early stages. The latest academic literature on blockchain in industry and economics is therefore analyzed in this article. We identify the most highquality articles, active countries and most popular keywords based on a comprehensive analysis of literature published on the Web of Science. In addition to that, the clustering analyses are carried out, and the following study areas has been identified: 'economic gain,' 'blockchain technology,' 'initial coin offerings', 'fintech innovation' and 'sharing economies'.
\end{abstract}

Keywords: Bitcoin, Blockchain, Cryptocurrency, Digital currency, Fintech innovation, Sharing economies.

\section{Introduction}

Never before in our history, the need for blockchain was felt so indispensable. Now, whole world has come to a standstill and life has been encapsulated in a digital platform. In which, the most quintessential being the financial transaction, as every nation across the globe has relied on a conventional method to felicitate their consumer needs. Introducing online facility for almost all the services became a new norm in the society as, it not only helped consumer but also reduced the time and energy required to perform the task. Nevertheless, with changing environment whole world has taken a tectonic shift regarding the way they functioned, particularly growing concerns for privacy by certain groups. The new social world has opened a new wound in the world with so many grave infringements of privacy. The protagonist in this saga was Social network, which has turned to be the most vulnerable place for people's privacy. This emergence of globalization and social interaction has its history from different country's experience during many centuries. For instance, since inception almost every nation had a conservative policy towards its economy. However, with changing scenario, the circumstances necessitated them to open their economy for the global world. As a result, it led to people being socially active and affirming more rights. This assertion led various movement across the globe yielding some muchneeded reforms in various countries. With the advent of 21 st century people's aspiration has grown exponentially. Their rights have become paramount and no infringement in any form, whatsoever the circumstances may, was acceptable by them. This quixotic utopianism made certain vested interest group think that they could extricate themselves completely from the intervention of government. As a consequence, the upheaval demands for a deregulated mechanism of financial institution started surfacing in the market. There were so many ventures by different fringe groups to realize this dream but they all failed miserably. The dream of a deregulated market was yet to realize. Until a revolutionary idea appeared in an uncanny way to the world. Nonetheless, before dwelling upon the nitty and gritty of this de novo concept it seems pertinent to discuss the way market functioned before its arrival.

A country's economy always entails its central bank who keep track of the cash and money flowing in the market. This helps them in tax collection and keeping track of the economy including inflation, deflation, certain monetary disparity, so on and so forth. Therefore, it has been widely misunderstood by people that the real characteristics of Bitcoin is its virtual nature. What defines Bitcoin's distinctive feature is the absence of central bank from it.

Most of the currencies within the world at the present, including the reserve currencies, are fiat currencies. The term 'fiat currencies' refers to currencies that are issued by a government, and therefore the government promises to pay the holder of such currencies, the same amount in gold, if needed. Thus, these currencies usually have a central regulatory body which issues them and are consequently called 'centralized'. In fact, at the top of the day, they have the worth, they have, because somebody said so (Plassaras, 2013). The fashionable state can make anything it chooses as acceptable currency, with no further backing of any kind, even without a reference to gold (Scheurer, 2011).

Therefore, one among the foremost striking features of cryptocurrency is that it weeds out the necessity for a trusted third party like a governmental agency, bank, etc. The cryptocurrency system collectively creates the units. The speed at which such units are created is defined beforehand and is publicly known, unlike the normal currencies where the govt or the authorized banks control the availability (Desai, 2013).

Bitcoin maintained its autonomy and prospered in market essentially because of one underlining technology i.e. Blockchain. It was blockchain who created that autonomy that 
bitcoin enjoys now. The mechanism devised by blockchain is virtually infallible and seems very promising for so many other fields, were such autonomy, transparency and security is needed. Thus, it would be appropriate to suggest that blockchain is a new revolutionary technology which is going to change the way this system functions (Lerner, 1947).

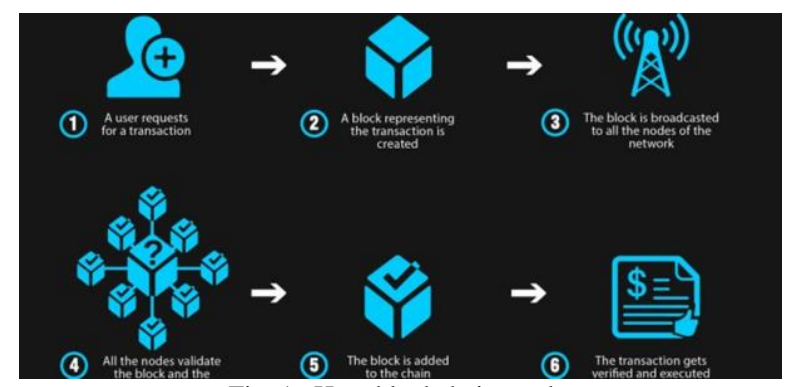

Fig. 1. How blockchain works

Source: https://101blockchains.com/ultimate-blockchain-technology-guide/

\section{Historical Background}

The concept of Bitcoin and Blockchain was first proposed in 2008 by a person using pseudonyms name Satoshi Nakamoto. It is an intelligent peer to peer network that uses distributed databases to identify, disseminate, and record information, also known as the value network. In 2008, in the aftermath of the subprime mortgage crisis, the confidence on the government issued currency and government's and bank's ability to manage the economy, the supply of money had almost hit rock bottom. Millions of dollars were used to bail out banks and insurance companies after the "quantitative easing" measures adopted by the Federal Reserve. This essentially meant that cash was being printed so as to stimulate the economy. The glut of currency backed with little or no economic productivity led to a worldwide recession ultimately precipitating a sovereign debt crisis in several countries. The worth of gold was constantly rising. At now, the paper by Satoshi Nakamoto was published online describing the Bitcoin for the primary time. As per the opinion of Nakamoto, the main problem with conventional currency today was that trust was required to let the system work. He makes it clear in his paper, that while watching the history of fiat currencies, one can see that it is filled with breaches of such trust. He further goes on to state that banks use the currency entrusted to them to lend it in 'waves of credit bubbles', with hardly anything left in reserve (Desai, 2013).

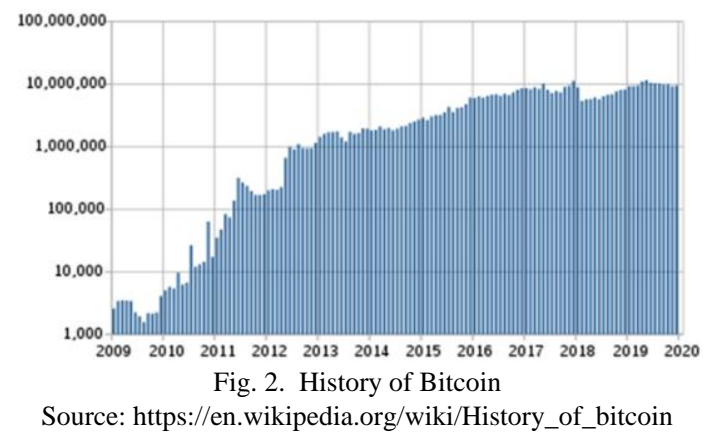

The introduction of this new concept was done in 2008, when global crisis has wreaked havoc on global economies and almost every country has taken a toll either directly or indirectly. This research paper initially was not taken seriously but later considering the bolstered mechanism it encompassed, it started getting attention from all spectrum of the society. There was a real buzz about the bitcoin in the year 2016-17 and the prices went as high as $\$ 20,000$. With rampage demand of bitcoin, the society started scrutinizing the mechanism it entailed such as not having a centralized controlling and its relatively infallible rate of transaction. This led to the shift of focus from Bitcoin to its underlining intelligence "Blockchain".

A shrewd observer would rather find the concept of Blockchain more revolutionary as compared to Bitcoin. As, the former could be used in almost every technology possible and will pave a way to advance the idea of digital world and safe and secure transaction between the people. Whereas, the latter strips of the right of the government and dilutes its presence from the economy.

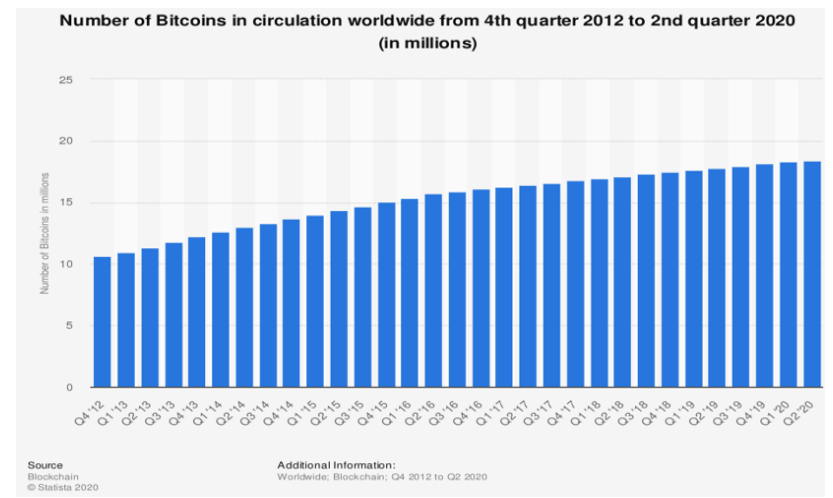

Fig. 3. Number of bitcoins are in use till 2nd quarter of 2020 Source: https://www.statista.com/statistics/247280/number-of-bitcoins-incirculation/

\section{Blockchain Technology}

The concept of the blockchain could be well understood by Bitcoin as it is intrinsically linked with each other. However, it must be borne in mind that the blockchain technology is applicable to any digital asset transaction exchanged online. When an individual makes any transaction via online method, the invariable result is that it will choose a security check to a third party.

Therefore, it is safe to mention that the third-party transaction may be a safeguard employed to validate, preserve and avoid any fraud transaction from the system. Whereas, in the case of bitcoin, it uses cryptographic proof rather than the trust-in-thethird-party mechanism for two willing parties to execute a web transaction over the web. Thus, blockchain facilitates the buyer to evade the third-party involvement and supply them a platform where consumers could interact within themselves with no surveillance. The blockchain may be a database that is shared across a network of computers. Once a record is added to the chain it is very difficult to vary. As an example, if a 
transaction is completed through bitcoin then each transaction is protected through a digital signature, that is shipped to the "public key" of the receiver, and is digitally signed using the "private key" of the sender. So as to spend money, the owner of the cryptocurrency must prove his ownership of the "private key". The entity receiving the digital currency then verifies the digital signature, which means ownership of the corresponding "private key," by using the "public key" of the sender on the respective transaction. Each transaction is broadcasted to each node within the Bitcoin network and is then recorded in relevant public ledger after verification. Every single transaction must be verified for validity before it is recorded in the public ledger (Michael Crosby, 2016). Now, each transaction in that ledger is verified by consensus of a majority of the participants within the system. Once entered, information can never be erased. The blockchain contains a particular and verifiable record of each single transaction ever made. To use a basic analogy, it's easier to steal a cookie from a cooky jar, kept in a secluded place than stealing the cookie from a cooky jar kept in a market place, being observed by thousands of individuals (Michael Crosby, 2016). Having said that, the most important misgivings for an in-depth scrutiny is that the privacy of the parties involved are going to be compromised. The shared consensus and anonymity are two important traits of blockchain technology. Which helps it to flourish in the market amidst the growing rate of encroachment in privacy by various state actors.

\section{Blockchain Utility on Various Platforms}

Even though Blockchain and bitcoin are always perceived analogous but there are galaxy of things that could be performed under blockchain, considering its reliability and autonomy. The task circumscribed in it can be both financial and non-financial. Currently, Blockchain technology is finding applications in both financial and non-financial areas that traditionally relied on a third party trusted online entity to validate and safeguard online transactions of digital assets.

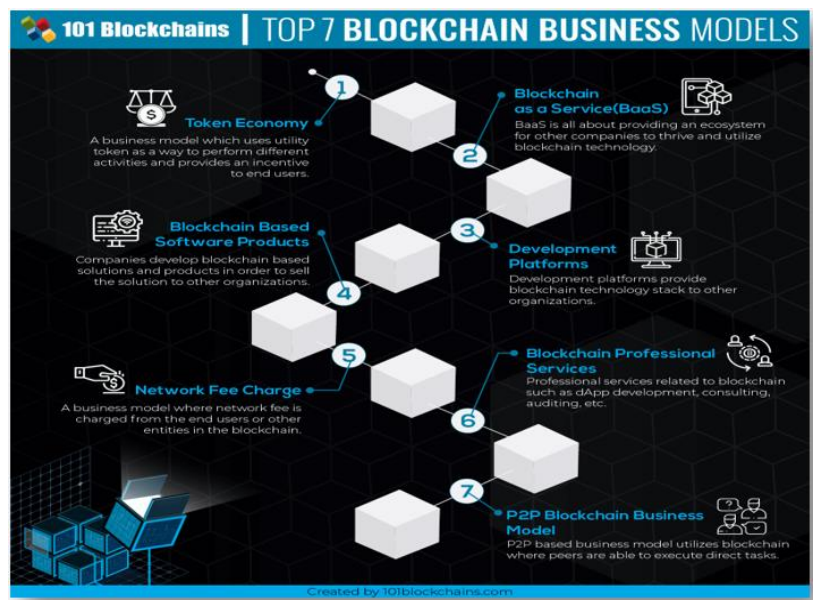

Fig. 4. Blockchain business models

Source: https://101blockchains.com/blockchain-business-models/
Besides, the real game changer in this slot is being smart contract. Earlier, so much of energy was exhausted in ensuring the compliance and subsequent release of fund, in which, manifold of formality enumerated was to be complied with. As a result, either that project will get delayed or it has to go through a rigorous scrutiny. Now, with the advent of blockchain this impediment could be done away with. Followings are the optimum use of this technology in various field.

\section{Smart Contract}

Smart Contract was invented in the year 1994 by Nick Szabo but was not that popular because of certain security issues. The nexus was to automatically execute contracts between the participating parties. With cryptocurrency in existence, the biggest hurdle faced by the smart contract seems to be fixed. Blockchain and smart contract can work in tandem by triggering payment when a preprogrammed condition of a contractual agreement is triggered. Therefore, these contracts are such, which will automatically be enforced by computer protocols. In particular, there were many cases where assets are transferred only after meeting certain conditions which require lawyers to create a contract and banks to provide Escrow services, can be replaced by smart Contracts (Michael Crosby, 2016).

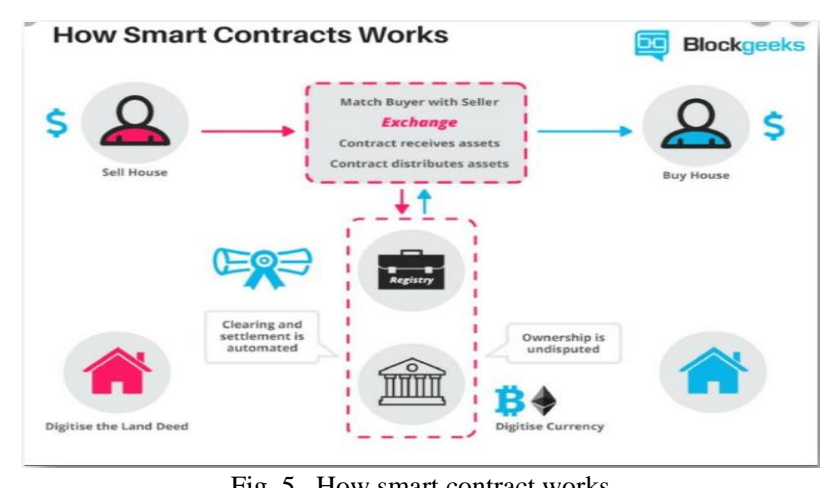

Fig. 5. How smart contract works

Source: https://www.optimum-web.com/what-is-ethereum-smart-contract/

\section{Notary Public}

The colossus task in India's legal system is the way files and different documents are stored. In particular, when a land document is endorsed to other party for sell. It is always received with suspicion. As, there is no benign method to check the authenticity of these documents. As a result, either a party has to go through a daunting task of inspection through layers of scrutiny or if he buys without caution, then subsequently through litigation. Which leads to loss of money and time.

Therefore, blockchain technology will revolutionize the way this redundant system functions. With its deployment, all the documents could be stored in a system, which would be immune from tempering and counterfeit. The document certification service helps in Proof of Ownership (who authored it), Proof of Existence (at a certain time) and Proof of Integrity 
(not tampered) of the documents. Since it is counterfeit-proof and can be verified by independent third parties, these services are legally binding. Using blockchain for notarization secures the privacy of the document as well as those who seek certification. By publishing proof of publication using cryptographic hashes of files into blockchain takes the notary time-stamping to a new level. Using blockchain technology also eliminates the need for expensive notarization fees and ineffective ways of transferring documents (Michael Crosby, 2016).

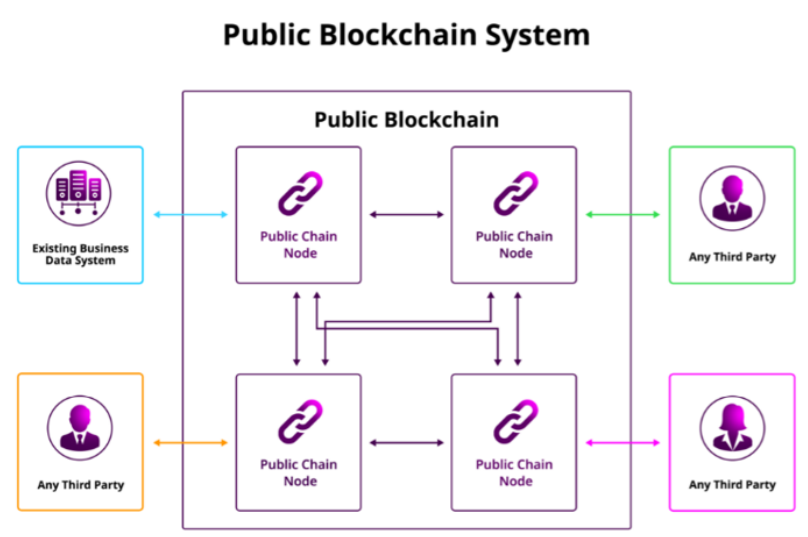

Fig. 6. Public blockchain system

Source: https://symbolplatform.com/latest/public-private-blockchainhybrid-systems-explained

\section{Blockchain Providing Solution for Rising Counterfeit Market}

Counterfeiting is one of the massive challenges in modern commerce. The market relating to counterfeit products is having a parallel existence as compared to the real market. Moreover, the rationale behind it seems to be the trust on a third-party entity, which culminates into a logical friction between merchants and consumers. The blockchain technology, with its decentralized feature and security capabilities, provides an alternative to existing anti-counterfeiting mechanism. Therefore, its successful application will rule out any manipulation from the third party and consequently, getting an exclusive safety of customers data. The authenticity of the brand will be preserved with the data stored in the blockchain and thus the need of a third party will vanish automatically.

\section{Relevance of Blockchain in Marketing}

The biggest difficulty market faces all these years is the breach of their customers data to various brand. Taking away the exclusivity these brands were enjoying until now. For instance, if a potential buyer visits one website in search of a particular item. Then this information will be leaked and disseminated either in public domain or to a competing brand. This has proliferated exponentially these days and the pursuit for data has become so paramount that it has opened a new multi dollar industry. Across the globe, multinational institutions are acknowledging that, "Data is a new Oil" and companies are employing manifold of techniques for snooping maximum data possible.

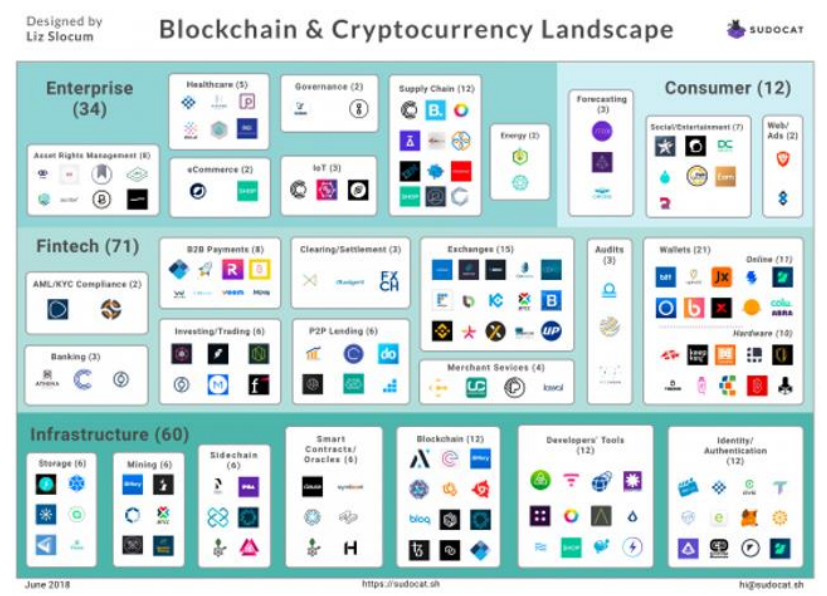

Fig. 7. Blockchain and Cryptocurrency market landscape Source: https://sudocat.sh/defining-the-blockchain-and-cryptocurrencymarket-landscape/

The conventional method till now was cookies, which gives the company the rough picture as to how many customers have visited their website and for which product. However, with increasing demand for privacy, companies started regulating the data and thus accessing cookies became a thing of a past. The concern for privacy has been lately acknowledged by various countries in which, the first being the Europe which has passed the General Data Protection Regulation (GDPR) laying down explicitly that the customers will have the exclusive right to give an express consent for his data and to confer power on any intermediary party.

The introduction of blockchain in marketing will revolutionize the industry and the way it functions currently. Considering blockchain, a kind of a ledger that will record and time-stamp every transaction and online interaction between one party and another. For instance, a customer can buy anything from any brand and subsequently give his consent for adding that information in the blockchain. Thereafter, there are various benefits and offer he could go for.

Firstly, the brand could update him for new arrivals or for any specific demand posed by the customer without his sensitive information coming into public domain or to some other company.

Secondly, the most important utility of blockchain in marketing would be the loyalty programs. Where the retailer could introduce its own virtual currency for customers to use in claiming rewards. As a result, customers can do shopping in any retail shop and in return he will get an exclusive rewards point, which would be applicable on his shop or in any of his branch.

Thirdly, the introduction of blockchain will facilitate one to one personification, as blockchain links all the transaction and online behaviors of customers. It will open a wide opportunity for the company to understand its customer's temperament and their expectation respectively. History replete with examples 
that those companies which were always in tune with their customers' aspiration burgeoned astoundingly. Hence, blockchain technology is an incredible medium, which holds the potential to transmogrify this field (Enochs, March, 2018).

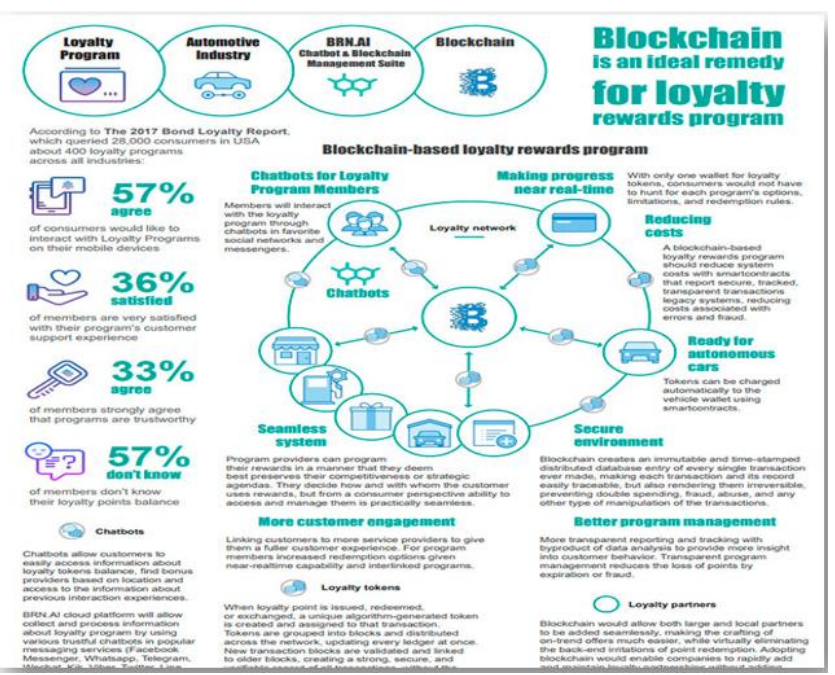

Fig. 8. Blockchain loyalty reward program

Source: https://brn.ai/blog/blockchain-loyalty-rewards-programs-automotiveindustry/

Percentage of Startups in Different Industries Focusing on Blockchain

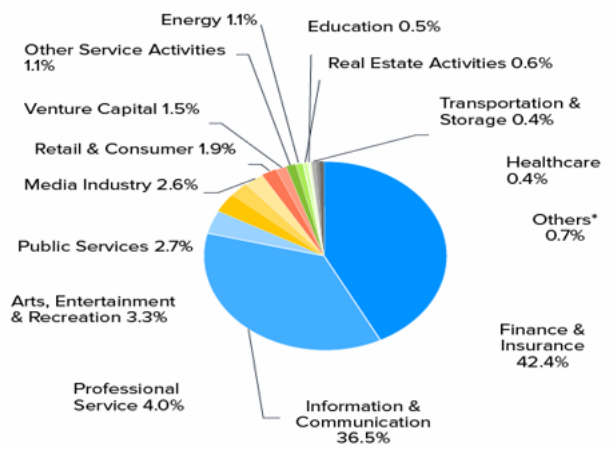

Fig. 9. Percentage of startups focusing on blockchain Source: https://appinventiv.com/blog/real-impact-of-blockchaintechnology-on-economy/

\section{Findings and Recommendations}

- Greater Transparency: The best feature of Blockchain is that Blockchain has a public key transaction chief. This adds unparalleled complexity in financial systems and companies and makes each segment of the enterprise responsible for behaving with dignity for the development of the enterprise, its society and its customers.

- Increased efficiency: Owing to its decentralized existence, in many processes for transfers and goods, Blockchain cancels out the need for intermediaries. Blockchain enables fast transactions, as opposed to conventional financial institutions, by facilitating cross-border $\mathrm{P} 2 \mathrm{P}$ payments of digital currency. With a single structure of ownership records and intelligent contracts automating tenant-landlord arrangements, property management procedures are made more effective.

- Better Security: As each new transaction is encrypted and connected to the previous transaction, Blockchain is much safer than other record keeping schemes. As the name means, Blockchain consists of a network of machines who enter together and validate a "block," and is added to a node that is a "line." Blockchain is a complex series of mathematical numbers that cannot be modified until it has been created. The immutable and incorruptible existence of blockchain eliminates counterfeit information and hacking. Decentralized existence also gives it a distinctly 'trustless' efficiency - which ensures that parties do not have to have trust to trade securely.

- Improved Transability: The blockchain database is accessible to track from where the goods come from any time an exchange of goods is reported on a Blockchain. This will not only boost protection and deter bribery in foreign exchange firms but can also help to check the validity of the goods exchanged. It can be used in industries such as pharmacy to chart the supply chain between suppliers and dealers, or it can provide a strong evidence of ownership in the art industry.

\section{Conclusion}

Every decade brings with itself some inevitable reforms with it. It certainly seems that the blockchain qualifies to be one of the much-needed reform. Nonetheless, the technology has always been considered as the side kick with Bitcoin being the protagonist. Introduced after the global recession of 2008, with underlining feature of its decentralized character. It was widely accepted by the certain section of people, who were aggrieved by the handling of Global Crisis. Without doubt, the timing of the concept was impeccable and the solution it entailed was gratifying. However, considering the circumstances we are in, it certainly seems that the Blockchain emerges as the real game changer. As discussed above, this technology's universal trait makes it perfect for any kind of work. Most importantly, it will act as a panacea to curb the menace of centralized authority and ubiquitous infringement of privacy.

\section{References}

[1] Desai, N., 2013. Bitcoin a global perspective, Nishith Desai Associates.

[2] Enochs, M., March, 2018. What is Blockchain and how is it changing Marketing?. Emarsys.

[3] Lerner, A. P., 1947. Money as a creature of the state. The American Economic Review, 37(2), pp. 312-317.

[4] Michael Crosby, N. P. P., 2016. Blockchain Technology: Beyond Bitcoin. Issue 2.

[5] Plassaras, N. A., 2013. Regulating Digital Currencies: Bringing Bitcoin within the reach of the IMF. Chicago Journal of International Law, 14(1).

[6] Scheurer, V., 2011. The Magic of Money: Can our current system of fiat money survive in the long term?. U.K: The Motley Fool. 